\title{
Susanne Janssen
}

Het soortelijk gewicht van kunst in een open samenleving

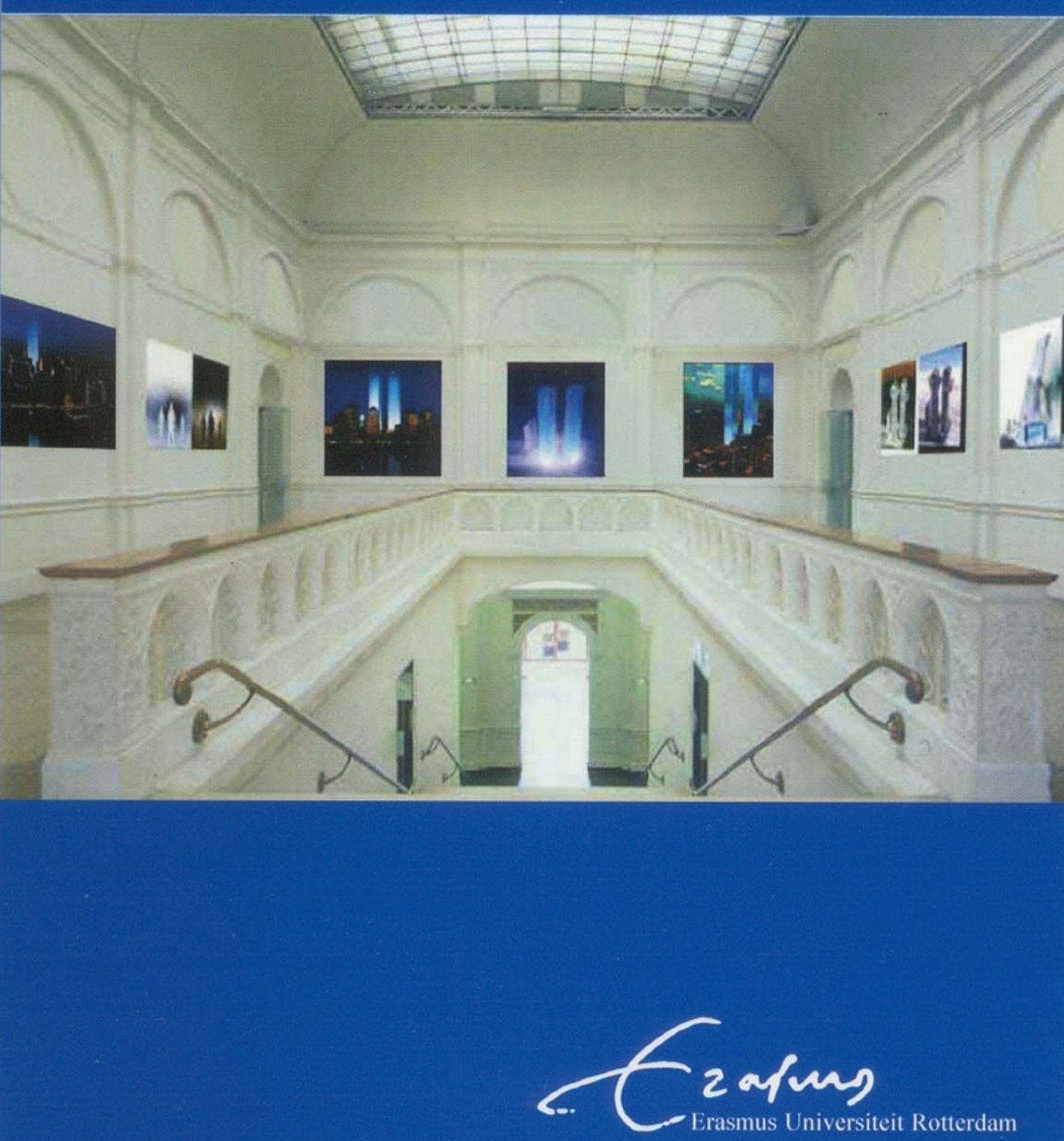


Copyright (C) Susanne Janssen, Rotterdam 2005

ISBN-10: 90-901-9818-0

ISBN-13: 97-890-901-9818-7

Niets uit deze uitgave mag worden verveelvoudigd, opgeslagen in een

geautomatiseerd gegevensbestand of openbaar gemaakt, in enige vorm of op enige wijze, zonder voorafgaande schriftelijke toestemming van de auteur.

Foto omslag: Filippo Panseca - September 2001 - Twin Towers of Light - Stedelijk Museum Amsterdam 


\section{Het soortelijk gewicht van kunst in een open samenleving}

De classificatie van cultuuruitingen in Nederland en andere Westerse landen na 1950

Rede uitgesproken bij de aanvaarding van het ambt van bijzonder hoogleraar in de

Sociale aspecten van Kunst, Cultuur en Media aan de Faculteit der Historische en Kunstwetenschappen van de Erasmus Universiteit Rotterdam op 18 maart 2005

door

Susanne Janssen 
Voor Borg 
Mijnheer de Rector Magnificus,

Dames en Heren,

In mijn academische loopbaan ben ik van meet af aan gefascineerd geweest door wat Pierre Bourdieu (1980) heeft omschreven als de 'productie van geloof': de symbolische productie van kunst en de complexe netwerken van personen en instanties die hierin een rol spelen. Hoe verlopen processen van selectie en oordeelsvorming, van beeldvorming, reputatievorming en canonvorming in de kunsten? Wat is de rol van de kritiek en media, het onderwijs, het publiek en van kunstenaars zelf in dit verband? Hoe verhouden deze partijen zich onderling en op welke wijze beïnvloeden zij elkaar? Welke conventies en waarden zijn richtinggevend voor de keuzes en oordelen van de diverse actoren binnen het culturele veld?

Gaandeweg ben ik er steeds meer van doordrongen geraakt dat je dit soort vragen niet los kunt zien van de bredere maatschappelijke context waarbinnen de waardering van kunst- en cultuuruitingen zich afspeelt. In de afgelopen anderhalve eeuw kende de oordeelsvorming over kunst een grotere autonomie dan in vroeger tijden, in die zin dat zij zich in toenemende mate is gaan voltrekken via eigen, specifieke principes en instituties. Maar de aard en maatschappelijke impact van die oordeelsvorming varieert in samenhang met wisselende maatschappelijke omstandigheden (Dorleijn en van Rees 1999). Niet alleen individuele cultuuruitingen, kunstenaars of genres worden in verschillende sociaal-historische settings anders gewaardeerd en geclassificeerd. Ook het karakter van die classificaties zelf en de functies die zij voor individuen en groepen mensen vervullen, zijn sterk maatschappelijk bepaald. Dat inzicht vormt het vertrekpunt van het VICI-onderzoeksproject, waaraan ik de komende jaren zal werken.* 


\section{Dimensies van culturele classificatiesystemen}

De wijze waarop cultuurproducten binnen een samenleving worden geclassificeerd kan verschillen op tal van punten. De Amerikaanse cultuursocioloog Paul DiMaggio (1987) heeft een viertal dimensies van culturele classificatiesystemen onderscheiden, waarop ik nader wil ingaan: hiërarchie, differentiatie, universaliteit en afgrenzingssterkte.

Om te beginnen variëren samenlevingen wat betreft de mate waarin cultuurvormen hiërarchisch zijn geordend. Sterk hiërarchische classificatiesystemen kenmerken zich door scherpe prestigeverschillen tussen genres. Sommige cultuurvormen genieten veel meer aanzien dan andere en ze ontvangen navenant meer steun en aandacht in het overheidsbeleid, kritiek en pers, onderwijs en wetenschap.

Samenlevingen verschillen verder in de mate waarin hun kunst is gedifferentieerd in institutioneel afgegrensde genres. Sterk gedifferentieerde classificatiesystemen kenmerken zich door een grote verscheidenheid aan genres en door sterk gesegmenteerde kunstwerelden.

Ten derde verschillen samenlevingen wat betreft de graad van maatschappelijke consensus over de klassering van cultuuruitingen. Universaliteit verwijst naar de mate waarin classificaties worden herkend en erkend door hun leden. We kunnen spreken van sterk universele classificatiesystemen wanneer mensen cultuurproducten op een homogene wijze indelen, ongeacht hun eigen voorkeuren. Velen houden van Baantjer, sommigen van Bordewijk, maar men stemt desalniettemin overeen in de klassering: lectuur versus literatuur. Bint prijkt op de recente $N R C$-lijst van boeken die iedereen, eigenlijk, gelezen moet hebben, De Cock niet (Mathijsen, Pleij en Vaessens 2005). De liefhebbers van Literatuur vinden we van oudsher vooral onder de hoger opgeleiden, maar het label literatuur had en heeft nog altijd een bredere rituele betekenis. In meer negatieve zin geldt dit ook voor een genre als 'romantische 
fictie' of voor sommige subculturele muziekgenres als punk, heavy metal of rap. Smaakverschillen binnen een samenleving hoeven dus geen beletsel te vormen voor een brede sociale (h)erkenning van culturele classificaties.

Zo kent de Franse maatschappij van de jaren zestig volgens Bourdieu (1979) een sterk universeel classificatiesysteem. Bourdieu toont in La Distinction niet alleen hoezeer culturele smaakverschillen samenhangen met verschillen in sociale positie. Hij beklemtoont tevens hoezeer andere lagen van de Franse bevolking het classificatiesysteem van de culturele elite onderschrijven (de Swaan 1986). Arbeiders, petit bourgeoisie en ook cultureel minder kapitaalkrachtige welgestelden demonstreren stuk voor stuk hun 'bonne volonté culturelle'. Ze spannen zich in om Bourdieu's enquêtevragen zo goed mogelijk te beantwoorden en de juiste componist of kunstenaar te noemen. Ze accepteren de elitaire indelingen in 'klassiek' en 'populair', 'serieus' en 'licht', 'hoog' en 'laag', hoewel die hun eigen voorkeuren declasseren. Andere classificaties zijn niet voorhanden. Volgens Bourdieu is met name het onderwijssysteem verantwoordelijk voor die algemene maatschappelijke erkenning van de legitieme cultuur, ook in die sociale lagen die er feitelijk een andere culturele smaak op nahouden. Bourdieu spreekt in dit verband van cultureel of symbolisch geweld. Het onderwijs leert kinderen uit de lagere sociale klassen om de eigen cultuur als minderwaardig te beschouwen.

De afgrenzingsdimensie van culturele classificatiesystemen, ten slotte, verwijst naar de mate waarin grenzen tussen genres zijn geritualiseerd: in hoeverre markeren genres symbolische afgrenzingen tussen groepen in de samenleving en zijn ze gekoppeld aan processen van sociale in- en uitsluiting? De rituele status van genreonderscheidingen valt af te leiden uit de intensiteit waarmee ze worden verdedigd door zowel producenten als publiek. Is er sprake van protest of onverschilligheid wanneer kunstenaars of intermediairs genreconventies doorbreken? In hoeverre worden genrevoorkeuren van andere groepen 
gerespecteerd of bestreden? Leidt dissident gedrag tot uitsluiting door peers of hebben afwijkende smaakvoorkeuren weinig of geen gevolgen?

DiMaggio (1987) brengt de onderscheiden dimensies van classificatiesystemen onder meer in verband met de sociale structuur en het onderwijssysteem van samenlevingen. $\mathrm{Hij}$ bouwt daarbij voort op Bourdieu's idee dat smaken nauw samenhangen met sociale posities. Via hun culturele voorkeuren maken mensen kenbaar bij welke sociale groep ze horen of willen horen. Maar omgekeerd zegt het geheel aan sociale posities ook iets over hoe in een samenleving wordt omgegaan met cultuur. Structurele eigenschappen van een samenleving, en uiteraard ook veranderingen hierin, manifesteren zich in de wijze van classificeren. Zo is Bourdieu's visie op de maatschappelijke realiteit in het algemeen en de culturele smaak in het bijzonder duidelijk geïnspireerd door een samenleving met een sterke verticale stratificatie en een onderwijssysteem waarin de nadruk vooral op Bildung lag.

Anders dan Bourdieu benadrukt DiMaggio juist de diachrone en synchrone variaties in de classificatie van cultuur. Classificeren geschiedt in elke samenleving, maar hoe dat gebeurt is tijd- en plaatsgebonden. Hoe meer een samenleving sociaal hiërarchisch is georganiseerd - op de werkvloer, in het onderwijs, in de dagelijkse omgang - des te sterker de hiërarchie in genres en des te sterker ook de afgrenzingssterkte van het classificatiesysteem.

Samenlevingen met een minder hiërarchische structuur kennen daarentegen een grotere verscheidenheid aan culturele genres, waarover minder overeenstemming bestaat. Ook zijn de grenzen tussen genres zwakker en de hiërarchische verschillen kleiner.

Dit zijn slechts een paar van DiMaggio's proposities inzake de relatie tussen kenmerken van samenlevingen en culturele classificatiesystemen. Het voert te ver om de overige hier allemaal te behandelen. DiMaggio's theorie is vooralsnog niet empirisch getoetst en inmiddels deels vervangen door 
benaderingen waarin meer nadruk ligt op de classificatiepraktijken van culturele industrieën (Bielby en Bielby 1994; Negus 1999; Baumann 2002). Niettemin lijken veel van zijn hypothesen nog altijd plausibel. Vergelijken we het hiërarchische Nederland van de vijftiger jaren met de meer egalitaire, open samenleving aan het begin van de $21 \mathrm{e}$ eeuw, dan lijkt de wijze van classificeren sterk op de door DiMaggio voorspelde situatie.

\section{Veranderingen in de classificatie van cultuur}

\section{Afname hiërarchische verschillen}

Anno 2005 is in Nederland nog altijd sprake van een hiërarchische ordening van genres. De afstand tussen de traditionele, hogere kunsten en voorheen minder legitiem geachte cultuurvormen is echter een stuk kleiner geworden. Sinds de jaren zestig van de vorige eeuw heeft zich een proces van onthiërarchisering voorgedaan. De vroegere, scherpe statusverschillen tussen cultuuruitingen zijn vervaagd en het domein van de legitieme cultuur is gaandeweg steeds meer genres gaan omvatten. In de afgelopen veertig jaar hebben onder meer film, fotografie, popmuziek, thrillers en strips onmiskenbaar aan prestige en erkenning gewonnen. Die opwaardering valt onder meer af te lezen aan de toegenomen aandacht voor de genoemde cultuurvormen in de dag- en weekbladpers (Janssen 1999), de uitbreiding van de steun die ze van overheidswege ontvangen (Pots 2000) en de grotere ruimte die ze krijgen toebedeeld in het voortgezet en hoger onderwijs.

Tussen 1965 en 1990 verviervoudigde bijvoorbeeld de ruimte voor popmuziek in de landelijke Nederlandse pers. Popmuziek verwierf een prominente plaats op de kunstpagina's van de betrokken kranten en streefde in een deel van de pers de klassieke muziek ruimschoots voorbij (Janssen 1999). Die toegenomen status kreeg vanaf de tweede helft van de jaren zeventig ook een beleidsmatige vertaling (Nuchelmans 2002). In 1977 kende minister van 
Doorn van CRM een ton subsidie toe aan de Stichting Popmuziek Nederland (SPN). De erkenning van overheidswege beleefde een volgende doorbraak met de reorganisatie van het orkestenbestel onder minister Brinkman. De SPN kreeg de benodigde middelen voor het zogeheten Podiumplan en een landelijk concours voor beginnende bands, De Grote Prijs van Nederland. In het kader van het eerste Kunstenplan in 1987 verwierf de Stichting een structurele subsidie van $€ 500.000$. Staatssecretaris Van der Ploeg maakte popmuziek tot beleidsprioriteit en verhoogde het budget tot $€ 2,2$ miljoen inclusief $€ 900.000$ voor het Nederlands Popmuziek Plan, de opvolger van het Podiumplan (OCW 2002).

In de loop van de jaren negentig veroverde popmuziek bovendien een steeds prominentere plek aan de Nederlandse conservatoria. In 1999 kreeg de popmuziek een eigen hogere beroepsopleiding. In Tilburg zag toen de Rockacademie het licht. Deze opleiding werd een jaar later erkend door het Ministerie van OCW, zodat studenten ook om popmuziek te leren een beurs aan kunnen vragen. Nog voordat de eerste lichting studenten van de Rockacademie afstudeerde, gingen op diverse plaatsen in Nederland soortgelijke opleidingen van start, al dan niet binnen bestaande muziekvakopleidingen (Mutsaerts 2004).

\section{Toegenomen differentiatie}

De afvlakking van hiërarchische verschillen tussen cultuurvormen is hand in hand gegaan met een toename van het aantal institutioneel afgegrensde genres en een groeiende differentiatie binnen het culturele veld. Enerzijds hebben gevestigde kunstsectoren zich vertakt in tal van gespecialiseerde subvelden. Binnen het domein van de beeldende kunst hebben zich bijvoorbeeld relatief autonome netwerken voor videokunst (Boomgaard en Rutten 2004) en nieuwe media kunst (computerkunst, webart) afgetekend met eigen instellingen en deskundigen. Anderzijds hebben voorheen minder legitiem of illegitiem geachte cultuurvormen zich in toenemende mate institutioneel georganiseerd. 
Zo beschikt het genre van het spannende boek in het Nederlandse taalgebied sinds 1980 over een eigen legitimeringinstantie in de vorm van de VN Detective en Thrillergids. Producenten en liefhebbers van misdaadromans kijken reikhalzend uit naar deze jaarlijkse bijlage, waarin de keurmeesters van Vrij Nederland het titelaanbod kritisch doorlichten en van een sterrenrating voorzien. In 1986 vestigden een aantal thrillerauteurs het Genootschap van Nederlandstalige Misdaadauteurs (GNM), dat inmiddels een gedifferentieerd stelsel voor de bekroning van Nederlandstalige misdaadliteratuur in het leven heeft geroepen. Na de instelling van de Gouden Strop voor het beste Nederlandstalige spannende boek in 1986, volgde in 1997 de Schaduwprijs voor de beste spannende debuutroman. In 2003 kwam er met de GNM Meesterprijs bovendien een oeuvreprijs. In datzelfde jaar werd ook de eerste publiekprijs voor het Nederlandse taalgebied geboren: de Zilveren Vingerafdruk, georganiseerd door www.crimezone.nl, de website voor en door thrillerfans, niet te verwarren met www.crime.nl, waar onder meer een online encyclopedie van thrillerauteurs is te vinden.

Naar analogie van de organisatie van de symbolische productie binnen de gevestigde kunsten zijn onder meer voor film, popmuziek en misdaadliteratuur zelfstandige institutionele circuits ontstaan, met eigen instellingen, tijdschriften, deskundigen, critici, prijzen, gidsen, naslagwerken, en wat dies meer zij. Ook de wijze van classificeren en beoordelen is gekopieerd met de ontwikkeling van kritische benaderingen en terminologieën, geënt op die binnen de gevestigde kunsten (Baumann 2001). Van eenrichtingsverkeer is hier overigens geen sprake. Op hun beurt hebben de gevestigde kunsten steeds meer elementen uit het domein van de commercieel geproduceerde populaire cultuur geïncorporeerd: bestsellerlijsten, boekentoptiens, consumentengidsen, wervende flyers, culturele agenda's, geavanceerde marketingtechnieken en grootschalige publiciteitscampagnes. Zowel in de klassieke podiumkunsten (Elffers, van der 
Hoeven en Ranshuysen 2004; Pol en Duijser 2004), de museumwereld (Mommaas 2000) als de literatuur (van Rees, Janssen en Verboord 2005) valt een toenemende oriëntatie op de markt, op vraag- en afzetmogelijkheden te bespeuren.

\section{Verlies aan universaliteit}

Met de erosie van hiërarchische verschillen en de groeiende verscheidenheid aan genres, is ook de consensus over de aard en kwaliteit van cultuuruitingen afgenomen. Het draagvlak voor traditionele culturele scheidslijnen is afgebrokkeld en nieuwe classificaties worden minder breed gekend en gerespecteerd dan vroeger. Dit verlies aan universaliteit manifesteert zich zowel binnen als buiten het culturele veld, zowel bij producenten als bij consumenten

Aan de publiekskant valt een groeiende segmentering waar te nemen. Westerse samenlevingen zijn in de afgelopen decennia steeds meer 'special interest' groepen gaan herbergen: publieksgroepen die zich richten op specifieke genres of 'sets' van producten en weinig of geen boodschap hebben aan andere vormen van cultuur. Dergelijke 'special interest' groepen wortelen voor een deel in nieuwe sociale of identiteitsbewegingen. In veel gevallen ontbreekt echter zo'n ideologische grondslag, maar gaat het om zogeheten smaakculturen of om groepen consumenten die clusteren rondom specifiek genres of producten: 'gratification sets' of 'fangroepen', zoals men ze in de communicatiewetenschap pleegt te noemen(McQuail 1997).

Dat laat onverlet dat de leden van dergelijke groepen vaak wel overeenkomen op sociologisch relevante kenmerken als leeftijd, opleidingsniveau, sekse en etnische herkomst. Recent onderzoek toont bijvoorbeeld dat de muzieksmaak van Nederlandse en Vlaamse jongeren nauw samenhangt met etnische achtergrond, leeftijd en geslacht (Crok et al. 2002; Elchardus, Faelens en Kuppens 2002). Zo zijn hiphop en wereldmuziek vooral in trek bij allochtone Amsterdamse jongeren, in het bijzonder bij de Surinaams/Antilliaanse groep. Ook Turkse jongeren hebben betrekkelijk vaak een voorkeur voor wereldmuziek. Van de autochtone jongeren in 
Amsterdam heeft daarentegen slechts een fractie affiniteit met deze muziekstijl.

Het verlies aan universaliteit komt heel pregnant tot uitdrukking in en is ook deels een product van de politiekemancipatorische strijd om de 'canon', zoals die sinds de jaren zestig in Nederland en andere westerse landen is gevoerd. De gevestigde culturele orde kwam decennialang onder vuur te liggen van opeenvolgende kritische bewegingen, die protesteerden tegen de culturele achterstelling van bepaalde groepen. Militante groepsleden en sympathiserende intellectuelen sprongen in de bres voor de cultuur van onder anderen arbeiders, vrouwen, zwarten, homo's en etnische minderheden.

Wat de gewraakte gevestigde cultuur en de gewenste hervormingen precies inhielden, verschilde per beweging en nationale context. Maar de talrijke geschriften uit de hoek van het neomarxisme, feminisme, black studies en andere minderhedenstudies kwamen overeen in hun afwijzing van heersende cultuuropvattingen en canons (Nochlin 1971; Vogelaar 1972; Meijer 1988; van Alphen en Meijer 1991; Gorak 1991; Lauter 1991). In tegenspraak met hun universalistische claims zouden die slechts de belangen van heersende elites dienen en de cultuuruitingen van andere groepen systematisch uitsluiten.

In de ogen van betrokkenen heeft hun strijd vermoedelijk maar ten dele de gewenste erkenning opgeleverd (Bryson 2005). Ze heeft echter wel twijfel gezaaid aan de legitimiteit van gevestigde culturele hiërarchieën en bijgedragen tot een meer pluralistisch cultuurbegrip, of zo men wil, tot cultuurrelativisme.

Naast deze maatschappelijk geëngageerde impulsen hebben ontwikkelingen binnen het wetenschappelijke veld geleid tot een grotere diversiteit aan kunst- en literatuuropvattingen en een tanend geloof in het bestaan van vaste culturele ijkpunten (Goedegebuure en Heynders 1996; Wilterdink 2000). Daardoor is het ook steeds minder evident geworden welke genres, kunstenaars of werken het 
onderwijs zou moeten overdragen. Die verminderde overeenstemming vinden we heel duidelijk terug in de praktijk van het Nederlandse literatuuronderwijs en de steeds weer terugkerende discussies over leeslijsten en de boeken die iedereen gelezen zou moeten hebben (Janssen 1998; Moerbeek 1998; Verboord 2003).

\section{Verminderde afgrenzingssterkte}

Zoals gezegd valt de afgrenzingssterkte onder meer af te lezen aan de mate waarin kunstproducenten en consumenten scheidslijnen tussen genres plegen te respecteren en protest aantekenen tegen grensoverschrijdingen. Zo beschouwd is de rituele betekenis van genreclassificaties binnen en buiten het culturele veld duidelijk afgenomen. Kunstenaars en culturele instellingen zijn minder gebonden aan genreconventies. Ze kunnen zich vrijer bewegen tussen genres, zonder dat dit negatieve gevolgen heeft. Grensoverschrijdend verkeer tussen kunst en massacultuur is sinds de jaren zestig steeds gebruikelijker, zo al niet een nieuwe norm geworden. 'Gerapte versies van Shakespeare, ballet op house muziek, symfonieorkesten die met popmusici samenwerken, romans met een zapstructuur, clips en reclamefotografie als kunst' (Franke 2000) oogsten eerder lof of een vermoeid schouderophalen, dan dat er nog aanstoot aan wordt genomen.

In de sfeer van de cultuurconsumptie is weinig veranderd aan het elitaire karakter van de belangstelling voor de traditionele hogere kunsten. De leden van de hogere statusgroepen zijn nog altijd sterk oververtegenwoordigd onder het publiek van klassieke muziek, toneel, dans, beeldende kunst en literatuur. Uit tal van studies blijkt tevens dat vooral het opleidingsniveau verantwoordelijk is voor deze differentiatie. De studies van het Sociaal en Cultureel Planbureau (Knulst en Kraaykamp 1996; de Haan en Knulst 2000; van den Broek, Huysmans en de Haan 2005) laten er geen misverstand over bestaan: van de hoger opgeleiden bezoekt een veel groter deel op zijn minst één maal per jaar een klassiek concert, toneelvoorstelling of dansuitvoering. 
Hetzelfde geldt voor het bezoek aan galeries en kunstmusea en het lezen van literatuur. De verschillen tussen hoger en lager geschoolden zijn in de afgelopen decennia ook niet noemenswaardig afgenomen. Zo bezien is 'kwaliteit' nog steeds 'klasse', zoals De Swaan (1986) La Distinction treffend parafraseerde.

Maar er is meer aan de hand. Hooggeschoolden bezoeken ook vaker populaire podiumkunsten zoals popconcerten en cabaretvoorstellingen en zijn dat in de loop van de tijd steeds meer gaan doen. De opkomst van de zogeheten 'culturele omnivoor' suggereert dat de afgrenzingsfunctie van genreclassificaties is afgezwakt. Trouwe krantenlezers kan nauwelijks ontgaan zijn wie of wat een culturele omnivoor is. Het fenomeen is meermalen bediscussieerd en gedefinieerd in de Nederlandse pers: 'de allesvretende cultuurmens is... een goed opgeleide veertigplusser die naar Mozart en naar popmuziek luistert, die naar de opera maar af en toe ook naar een Endemol-musical gaat en die Homerus even weglegt omdat er op SBS een lekkere shitfilm begint' , aldus de schrijver Herman Franke (2000) in NRC Handelsblad.

In het perspectief van Bourdieu participeren de beter opgeleiden en welgestelde burgers deels om statusredenen aan het kunstaanbod. Door een exclusieve voorkeur voor hogere, 'legitieme' cultuur te belijden onderscheidt de elite zich van andere sociale klassen. Middengroepen die een hogere status nastreven, plegen zich naar dit elitaire voorbeeld te richten. Maar voor jongere generaties hoger opgeleiden lijkt deze stelling niet langer op te gaan. Zij trekken geen scherpe grens meer tussen de elitaire en populaire cultuuruitingen. Ze vertonen een brede smaak, die zich allerminst beperkt tot de conventionele hogere kunsten. 'Kwaliteit' is misschien nog wel steeds klasse, maar klasse is minder 'kwaliteit', als we gemakshalve 'kwaliteit' en 'traditionele kunst' aan elkaar gelijkstellen.

De culturele omnivoor werd voor het eerst gesignaleerd in de Verenigde Staten. Toen Richard Peterson begin jaren negentig het verband tussen sociale status en 
muziekvoorkeuren onderzocht (Peterson en Simkus 1992), vond hij een ander resultaat dan hij op basis van Bourdieu's La Distinction verwachtte. De hogere statusgroepen bleken zowel van 'hogere', klassieke muziekgenres als van populaire muzieksoorten te houden. In plaats van de veronderstelde exclusieve voorkeur, vertoonden ze juist een brede smaak die Peterson als 'omnivoor' typeerde. De lagere statusgroepen gaven daarentegen blijk van een 'univore' muzieksmaak: hun voorkeuren beperkten zich tot hooguit een paar populaire genres. In een vervolgstudie constateerden Peterson en Kern (1996) dat de omnivore smaak onder hoger opgeleide Amerikanen tussen 1982-1992 steeds verder was opgerukt, in het bijzonder bij jongere cohorten.

Ander Amerikaans onderzoek completeerde het beeld door niet de muzikale voorkeuren, maar juist de afkeren van mensen te onderzoeken (Bryson 1996; 1997). Mensen uit de hogere statusgroepen vertoonden niet alleen meer voorkeuren, maar ook minder afkeren. Toch bleek ook hun tolerantie zijn grenzen te kennen: van de muzieksmaak van de laagst opgeleiden moesten ze weinig hebben, of zoals de onderzoekster haar onderzoek kernachtig samenvatte: 'Anything, but heavy metal'.

Inmiddels heeft ook in andere Westerse landen het nodige onderzoek plaatsgevonden naar het verschijnsel van de culturele omnivoor (Bennet, Emmison en From 1999; van Eijck 1999; van Rees, Vermunt en Verboord 1999; van Eijck 2001; Lopez-Sintas en Garcia-Alvarez 2002; Coulangeon 2003; 2004; Vander Stichele en Laermans 2004). De resultaten daarvan sporen in grote lijnen met de bevindingen van Peterson en de zijnen. Jongere generaties hoger opgeleiden manifesteren steeds minder vaak een exclusieve voorliefde voor traditionele hogere cultuuruitingen, maar tonen zich in toenemende mate geïnteresseerd in populaire cultuur.

De termen 'manifesteren' en 'tonen' zijn hier bewust gebruikt. Culturele omnivoriteit is geen verschijnsel van de 
laatste twintig of dertig jaar. Hoogopgeleide kunstliefhebbers uit de jaren vijftig en zestig onthielden zich evenmin van 'lagere' cultuur; een aanzienlijk deel van hen las 'ongepaste' boekengenres, luisterde naar radiosoaps en frequenteerde de bioscoop (van Eijck, de Haan en Knulst 2002). Maar anders dan tegenwoordig beleden deze omnivoren avant la lettre hun populaire voorkeuren in stilte; ze waren niet bon ton en al te openlijke manifestatie ervan kon tot prestigeverlies leiden.

Hoe gangbaar het omnivore smaakpatroon vandaag de dag is en hoe het zich verder zal ontwikkelen valt lastig te zeggen. Het antwoord op deze vragen hangt niet in de laatste plaats af van de gehanteerde definitie: Wie of wat is een omnivoor? Het Sociaal Cultureel Planbureau ging in 2000 na welk deel van de Nederlandse bevolking het bezoek aan klassieke podiumkunsten en musea in de jaren tachtig en negentig combineerde met deelname aan populaire podiumkunsten. Aldus gedefinieerd, kon in 1983 en 1995 respectievelijk $14 \%$ en $17 \%$ van de Nederlanders als cultureel omnivoor worden beschouwd (de Haan en Knulst 2000).

Vlaams cultuurparticipatieonderzoek liet zien dat anno 2001 om en nabij de $10 \%$ van de bevolking zeer frequent deelnam aan zowel hoge als lage cultuur (Vander Stichele en Laermans 2004). Volgens de onderzoekers zijn dit de ware omnivoren. Daarnaast vertoonde circa een kwart van de Vlamingen een omnivore oriëntatie. Maar afgezien van bioscoopbezoek en deelname aan popconcerten participeerde deze groep niet op een heel actieve manier aan de onderzochte cultuurvormen. In termen van dit onderzoek vertoonde dus circa $35 \%$ van de Vlaamse bevolking een min of meer omnivoor cultureel gedragspatroon. In tegenstelling tot hun Nederlandse collega's namen de Vlaamse onderzoekers ook bioscoopbezoek mee in de meting van populaire cultuurdeelname. Het hogere percentage omnivoren in Vlaanderen hangt hier ongetwijfeld mee samen.

Van Eijck, De Haan en Knulst (2002) betrokken nog meer culturele activiteiten in de analyse, waaronder ook 
allerlei activiteiten binnenshuis. Met die operationalisering kwam het aandeel omnivore Nederlanders anno 1999 uit op $68 \%$, bijna het dubbele van de $35 \%$ uit het Vlaamse onderzoek en vier keer zoveel als de $17 \%$ 'omnivoren' die het SCP voor 1995 noteerde. De betrekkelijkheid van cijfers is hiermee nog maar eens aangetoond.

Uit het zojuist genoemde Nederlandse onderzoek komt echter één ding duidelijk naar voren: jongere generaties Nederlanders, ook de hoger opgeleiden onder hen, doen verhoudingsgewijs steeds minder aan conventionele hoge cultuur en steeds meer aan allerlei andere vormen van cultuur en ontspanning. Met name hooggeschoolde jongeren ondernemen veel verschillende activiteiten en hebben een brede smaak. Vaak zijn zij echter geen 'omnivoren' in de zin dat ze volop participeren aan zowel de hogere als de populaire cultuur. Volgens die definitie zijn het vooral oudere lichtingen hoger opgeleiden die een 'omnivore' smaak vertonen en hoog en laag naar hartelust combineren. Onder jongere hooggeschoolden slinkt de groep met een brede interesse voor zowel hoge als populaire cultuur; de groep die zich overwegend of uitsluitend op populaire cultuur richt, groeit daarentegen gestaag.

In Nederland lijkt het omnivore smaakpatroon dus al weer op zijn retour, anders dan de studies van onder anderen Peterson (1997) en Schulze (1992) deden verwachten. Steeds meer jongere hooggeschoolden voelen het zich niet aan hun status verplicht om zich exclusief, intensief of überhaupt met kunst bezig te houden - of op zijn minst te doen alsof. Niet dat alles kan, want heavy metal blijft not done voor het gros van de beter opgeleiden, maar de traditionele waterscheiding tussen hoge en lage cultuur lijkt voor hen nauwelijks nog een rol te spelen. 


\section{Crossnationale verschillen}

In de tweede helft van de twintigste eeuw hebben zich dus grote veranderingen voorgedaan in het Nederlandse culturele classificatiesysteem. Overeenkomstige ontwikkelingen vallen waar te nemen in andere Westerse landen, maar ze hebben zich niet overal in gelijke mate of gelijktijdig gemanifesteerd.

Zo suggereert longitudinaal onderzoek naar de positie van hoge cultuur in de Verenigde Staten (Levine 1988; DiMaggio 1991; Dowd 2002; DiMaggio en Mukhtar 2004) en vergelijkend onderzoek naar evaluatieve repertoires in Frankrijk en de VS (Lamont en Thévenot 2000) dat traditionele cultuuropvattingen en hiërarchieën in Frankrijk pas later en ook minder sterk zijn geërodeerd dan in de Verenigde Staten. Hoewel binnen het Franse culturele veld de gerichtheid op de markt in recente jaren is toegenomen en er meer aandacht is gekomen voor etnische en raciale diversiteit, lijken Franse cultuurexperts nog altijd veel minder geneigd of bereid om cultuurproducten op hun 'commerciële' of 'multiculturele' kwaliteiten te beoordelen dan in de Verenigde Staten (Pinto 1988; Lamont 1992). Vergeleken met hun Amerikaanse collega's blijken Franse uitgevers en literatuurwetenschappers bijvoorbeeld veel sterker gericht op de traditionele literaire canon en ze achten verwijzingen naar de markt of groepskenmerken minder opportuun of zelfs ontoelaatbaar als het gaat om de beoordeling van literatuur (Duell 2000; Weber 2000; Obbema 2003).

In termen van DiMaggio (1987) lijkt de terugval in 'hiërarchie' en 'universaliteit' in Frankrijk dus een stuk minder groot dan in de Verenigde Staten. Comparatief Europees onderzoek wijst erop dat Frankrijk op de genoemde dimensies ook duidelijk verschilt van Nederland. Een vergelijkende analyse van het kunstonderwijs aan middelbare scholieren in de afgelopen vijftien jaar (Bevers 2005) toont bijvoorbeeld dat eigentijdse, populaire vormen van beeldende kunst en muziek in het Nederlandse curriculum prominenter aanwezig zijn dan in het Franse. Wellicht blijft om die reden 
in ons land de deelname van jongeren aan traditionele kunstvormen veel sterker achter bij het bevolkingsgemiddelde dan in Frankrijk (SCP 2000).

Dit soort transnationale verschillen vraagt om systematisch, vergelijkend onderzoek, dat de classificatie van cultuuruitingen in samenhang beziet met bredere structurele en culturele kenmerken van de betrokken samenlevingen. Met mijn VICI-project Cultural Classification Systems in Transition hoop ik in de komende periode een impuls aan de uitbouw van dit soort onderzoek te geven. In het hiernavolgende richt ik me primair op Nederland.

\section{Drijvende krachten achter veranderingen in classificatie}

De geschetste veranderingen in het Nederlandse classificatiesysteem zijn het resultaat van diverse, onderling verweven bredere maatschappelijke processen en daarmee verbonden ontwikkelingen binnen het culturele veld zelf. De bedoelde bredere, maatschappelijke processen laten zich (deels) samenvatten als een toegenomen 'openheid' van de samenleving.

$\mathrm{Nu}$ is maatschappelijke openheid niet alleen een relatief, maar ook een meerdimensionaal begrip. In de sociologische literatuur wordt de term meestal gebruikt in samenhang met sociale stratificatie en sociale mobiliteit (Munters 1977). In een gesloten samenleving ligt iemands sociale positie vanaf de geboorte vast en kunnen mensen niet stijgen of dalen op de maatschappelijke ladder; in een open samenleving daarentegen staan sociale posities in beginsel open voor iedereen en komt sociale stijging of daling veelvuldig en zeer algemeen voor.

Zo bezien heeft zich in de loop van de naoorlogse periode een duidelijke verschuiving afgetekend naar een meer open samenleving, zowel in normatieve als in feitelijke zin (Dronkers en Ultee 1995). De opvatting dat 'God de standen heeft gewild' raakte vanaf de jaren vijftig in 
diskrediet. In plaats daarvan werd 'gelijke kansen voor iedereen' de norm: niet de sociale afkomst, maar persoonlijke capaciteiten (het 'verborgen talent') en onderwijsprestaties dienden voortaan de maatschappelijke positie van mensen te bepalen (van Kemenade et al. 1986; Schuyt en Taverne 2000).

Maar de grotere openheid van de samenleving behelst niet alleen verminderde sociale ongelijkheid en toegenomen sociale mobiliteit. De term verwijst ook naar processen van ontvoogding, individualisering, onthiërachisering die in diezelfde periode op gang kwamen. Deze ontwikkelingen hebben grote consequenties gehad voor het socialisatieklimaat waarin jongere generaties Nederlanders zijn grootgebracht. Ze liggen daarmee aan de basis van de veranderingen in het Nederlandse culturele classificatiesysteem. Ik kom daar zo meteen op terug.

Welvaartstijging en expansie van het aanbod Een eerste cruciale ontwikkeling in dit verband is de naoorlogse welvaartsstijging, die uitmondde in een indrukwekkende expansie van de mogelijkheden voor cultuurconsumptie en vrijetijdsbesteding (Knulst 1989).

Evenals andere westerse landen, beleefde Nederland vanaf de jaren vijftig een snelle en aanhoudende welvaartgroei. Mensen konden steeds gemakkelijker in hun eerste levensbehoeften voorzien en kregen meer vrije tijd. De vroegere nadruk op arbeid, zuinigheid, en zekerheid kwam te vervallen. In plaats daarvan ontwikkelde zich een consumptiecultuur naar Amerikaans model (Schuyt en Taverne 2000). Tussen 1950 en 1970 vervijfvoudigden de consumptieve bestedingen. Het bezit en gebruik van audiovisuele apparatuur en andere duurzame gebruiksartikelen steeg spectaculair, mede onder invloed van nieuwe en gewilde Amerikaanse producten, die na 1950 op de Nederlandse markt kwamen. In 1957 had nog geen 10\% van de Nederlandse huishoudens een televisietoestel in huis. Drie jaar later was er al in een kwart van de huishoudens een 
zwartwittoestel aanwezig, terwijl rond 1965 twee derde van de huishoudens over een toestel beschikte (Wijfjes 1994).

De steeds algemenere verbreiding van radio, grammofoon en televisie droeg sterk bij tot de doorbraak van de populaire cultuur in Nederland (Righart 1995). Televisiekijken zelf groeide uit tot de populairste vrijetijdsbesteding. Tienerkamers, pick-ups en draagbare radio's boden jongeren de gelegenheid om ongestoord en wanneer ze maar wilden naar hun favoriete muziek te luisteren en bevorderden zo de opkomst van een jeugdcultuur (Tillekens 1990).

Mensen kregen niet enkel meer vrije tijd, maar konden bovendien steeds meer geld aan die vrije tijd spenderen. De vrije tijd verscheen daardoor als een zelfstandig segment op de markt van goederen en diensten. De groeiende particuliere, publieke en commerciële bemoeienis met de vrije tijd resulteerde in steeds meer mogelijkheden voor de besteding ervan (Beckers en van der Poel 1992). Voor dit groeiende aanbod van cultuur en ontspanning waren in eerste instantie vooral de overheid en het particuliere initiatief verantwoordelijk en in minder mate commerciële aanbieders (Knulst 1989). Vanaf de jaren vijftig ontstond een uitgebreide infrastructuur van door de overheid gesubsidieerde culturele instellingen en andere vrijetijdsvoorzieningen. Evenals het welzijnswerk, de sport, de recreatie en de media, ontwikkelde de kunst zich tot een zelfstandige sector, met eigen opleidingen, organisaties, regels en praktijken en een eigen afstemming tussen overheid en particuliere sector (Mommaas 2000).

Op deze periode van verstatelijking (Oosterbaan Martinius 1990) volgde vanaf de jaren tachtig echter een fase van ontstatelijking en vermarkting (Boorsma, van Hemel en van der Wielen 1997). Processen van decentralisatie, privatisering, deregulering, liberalisering en economisering dwongen publieke instellingen om meer marktconform te opereren. Tot die instellingen behoorden onder meer de 
publieke omroep (de Goede 1999), musea (Bos 2001) en podiumkunstinstellingen (van Dulken 2002).

De traditionele hoge cultuur raakte niet alleen sterker aangewezen op eigen inkomsten, maar belandde tevens in een steeds scherpere concurrentiestrijd om de aandacht van de consument. Die verhevigde concurrentie was deels een gevolg van het sterk uitgedijde aanbod van producten en diensten op allerlei deelmarkten: het toegenomen aantal boektitels, films, tijdschriften, televisieprogramma's, tentoonstellingen, festivals, dagattracties, evenementen, vakantiebestemmingen, enzovoorts. Dankzij de snel gegroeide verbreidingsmogelijkheden kregen culturele producten een veel groter bereik. Mensen kwamen steeds meer in aanraking met cultuuruitingen van elders en konden een bredere keuze maken uit het groeiende, transnationale aanbod.

Ze kregen bovendien een steeds grotere fysieke en communicatieve actieradius door het toegenomen bezit en gebruik van auto's en goedkope vliegtickets en de digitalisering van informatie en nieuwe technieken waarmee complexe producten gemakkelijker ontwikkeld en gedistribueerd kunnen worden (Mommaas 2000). Dat impliceerde op zichzelf al een toename van de mogelijkheden voor vrijetijdsbesteding en beleving en daarmee een grotere tijdsdruk. Die druk werd verder opgevoerd door het groeiende aantal tweeverdieners dat te maken kreeg met een daling van de vrije tijd (van den Broek en Breedveld 2001).

Producenten en instellingen in het culturele veld zijn gaandeweg steeds meer marktgericht gaan opereren om die verscherpte concurrentie het hoofd te kunnen bieden. Dat geldt voor kunstmusea, theaters, orkesten, toneelgezelschappen of literaire uitgevers, maar bijvoorbeeld ook voor de kunst en cultuurberichtgeving in dag- en weekbladen (Szanto 2000; van Dijk en Janssen 2001). Het accent is verschoven naar producten en formats waarmee men denkt een groter publiek aan te spreken. De daartoe aangewende strategieën lopen soms sterk uiteen. Het 
achterliggende doel is echter hetzelfde, of het nu gaat om culturele agenda's, bestsellerlijsten, met veel publiciteit omgeven literaire prijzen, megatentoonstellingen of de festivalformule. Ze zijn stuk voor stuk bedoeld om de aantrekkingskracht op het publiek, en vooral het jongere deel daarbinnen, te vergroten.

Hoe legitiem die pogingen op zichzelf ook zijn, ze hebben wel als effect dat de kunsten steeds meer verschijnen als 'commodities' die inwisselbaar zijn met allerlei andere, commerciële vrijetijdsproducten. De twijfel over de bijzondere status van kunst en de geldigheid van traditionele scheidingen tussen hoge en lage cultuur is hierdoor ongetwijfeld versterkt.

Democratisering onderwijs en toegenomen sociale mobiliteit Een andere ontwikkelingslijn in de opkomst van minder hiërarchische en meer gedifferentieerde patronen van cultuurproductie en cultuurconsumptie betreft de democratisering van het onderwijs en de toegenomen sociale mobiliteit. Vanaf de jaren vijftig en zestig kwam de democratisering van het Nederlandse onderwijs op gang (Schuyt en Taverne 2000). Middelbare en hogere opleidingen, die tot dan waren voorbehouden aan jongeren uit meer gegoede milieus, werden ontsloten voor jongeren uit alle sociale lagen.

Met de invoering van de zogenaamde Mammoetwet in 1968 raakte dit proces in een stroomversnelling. De Wet behelsde een ingrijpende herziening van het Nederlandse onderwijsstelsel, dat tot dan nog sterk naar de vroegere standenmaatschappij was gemodelleerd. Mulo, mms en hbs maakten plaats voor mavo, havo en vwo. Naast het gymnasium, kwam er een atheneum als voorbereiding op een universitaire studie. Brugklas en brede scholengemeenschappen maakten het eenvoudiger om over te stappen naar andere schooltypen en diverse opleidingen te stapelen.

Sindsdien is de deelname aan het algemeen vormend middelbaar onderwijs explosief gestegen (Ganzeboom 1996). 
Steeds meer jongeren verwierven een diploma dat toegang gaf tot een studie in het hoger onderwijs. Als gevolg hiervan nam ook de instroom in het wetenschappelijk en hoger beroepsonderwijs sterk toe. Opleiding groeide uit tot de belangrijkste determinant van de beroepsstatus van mensen: onderwijskansen worden weliswaar nog altijd beïnvloed door milieu van herkomst, maar die samenhang is veel minder sterk dan vroeger. Veel mensen kwamen zodoende in een andere maatschappelijke positie terecht dan hun ouders.

De verminderde belangstelling voor traditionele kunstvormen en de opwaardering van populaire cultuurvormen zijn deels te beschouwen als culturele neveneffecten van sociale mobiliteit. De groep hoogopgeleiden is sinds de jaren zestig veel heterogener geworden. De groep die de traditionele hoge cultuur met de paplepel heeft ingegoten gekregen is geslonken, terwijl een groeiend aantal hoger opgeleiden van huis uit vooral vertrouwd is met populaire cultuuruitingen.

Lang is gesteld dat sociale klimmers geneigd zijn om zich de hoge cultuur zo snel mogelijk eigen te maken en zich aldus te distantiëren van het milieu van herkomst. Recent onderzoek wijst echter in een andere richting (van Eijck 1999). Stijgers op de maatschappelijke ladder tonen minder interesse voor gevestigde cultuurvormen en doen meer aan populaire cultuur dan hoger opgeleiden die weinig of geen sociale mobiliteit hebben ervaren. De laatste groep is in de loop van de tijd steeds meer een minderheid gaan vormen binnen de hogere statusgroepen. Dit compositie-effect verklaart wellicht waarom het gestegen opleidingsniveau niet heeft geleid tot een evenredige toename in de belangstelling voor gevestigde kunstvormen, maar veeleer gepaard is gegaan met een opwaardering van populaire cultuurvormen.

De sterke invloed van de socialisatie in het gezin van herkomst lijkt er verantwoordelijk voor dat sociale klimmers eerder populaire cultuur hebben opgestuwd langs de maatschappelijke ladder, dan dat ze zich onderweg legitieme cultuur hebben toegeëigend om de tocht te versnellen of op hun bestemmingsplaats niet uit de toon te vallen. Naarmate 
meer mensen hetzelfde opwaartse sociale traject doorliepen, verminderde de druk om via deelname aan hogere cultuur de nieuw verworven sociale status te onderstrepen.

Emancipatie, individualisering en onthiërarchisering Zoals gezegd heeft de toegenomen openheid van de Nederlandse samenleving ook betrekking op processen van emancipatie, individualisering en onthiërarchisering die vanaf de jaren vijftig op gang kwamen.

De sterke welvaartsgroei maakte mensen kritischer en gevoeliger voor eigen beslissingen (Schuyt en Taverne 2000). Tal van groepen in de Nederlandse samenleving werden zich meer bewust van hun ondergeschikte positie en konden zich vervolgens emanciperen. Hoewel die emancipatie zich in eerste instantie langs collectieve lijnen voltrok, leidden de gestegen levensstandaard en consumptie(mogelijkheden) tot veel meer zelfstandigheid en individuele speelruimte dan vroeger. Ook de verbeterde onderwijsdeelname en rechtspositie droegen bij tot een onafhankelijker houding en meer keuzevrijheid.

Het collectieve verzet van de jaren zestig baande de weg voor een veel verdergaande individualisering in de daaropvolgende decennia. Het individualisme groeide uit tot een massaverschijnsel, mede door nieuwe communicatiemedia en nieuwe productietechnieken.

Traditionele instituties van de samenleving zoals de familie, buurtgemeenschap, kerk, politieke partij en vakbond verloren steeds meer hun bindende en identiteitverlenende functie (Giddens 1991). Voorheen boden deze instituties mensen een min of meer vanzelfsprekend handelingsrepertoire voor hun bestaan. Hun levensloop was al voor een belangrijk deel uitgestippeld door vastgelegde verwachtingspatronen. "Je had niets te kiezen", zeggen oudere mensen vaak als ze terugblikken op hun leven.

Maar traditionele voorschriften, gewoonten, rollenpatronen en zingevingskaders gingen steeds minder een richtsnoer vormen voor het individuele doen en laten. De standaardbiografie maakte plaats voor de keuzebiografie 
(Beck 1986; Beck en Beck-Gernsheim 2002). Mensen hebben meer ruimte - en ook de verplichting - gekregen om zelf invulling te geven aan hun bestaan: voor soort opleiding en werk, wel of geen gezin en kinderen, enzovoorts. Op allerlei gebieden mogen en moeten ze kiezen uit een groter palet aan mogelijkheden dan vroeger. Zo ook wat vrijetijdsbesteding en cultuurconsumptie betreft.

Individualisering heeft tevens bijgedragen tot een toenemende perceptie van onderlinge gelijkheid. Die 'onthiërarchisering' van menselijke betrekkingen komt onder meer tot uitdrukking in meer egalitaire en lossere omgangsvormen: mensen gaan meer op voet van gelijkheid en informeler met elkaar om (Schnabel 2004). Het ontzag voor autoriteiten is afgenomen. Mensen werden eigenzinniger en minder onderdanig. Gezagsdragers gingen zich op hun beurt inschikkelijker gedragen. De Swaan (1979) heeft dit proces omschreven als de overgang van een bevels- naar een onderhandelingshuishouding. Opvoeders, leraren, bazen en bestuurders kunnen steeds minder volstaan met het geven van bevelen, maar moeten vaker onderhandelen om iets van jongeren, werknemers of burgers gedaan te krijgen.

\section{Veranderingen in het (culturele) socialisatieklimaat}

Onderwijsdemocratisering, individualisering en onthiërarchisering hebben grote gevolgen gehad voor het opvoedings- en onderwijsregime waaronder Nederlandse jongeren vanaf de jaren zestig opgroeiden. Dit gewijzigde socialisatieklimaat lijkt in hoge mate verantwoordelijk voor de gesignaleerde veranderingen in de classificatie van cultuur. Deze these is met name door onderzoekers van het Sociaal Cultureel Planbureau uitgewerkt en empirisch onderbouwd (de Haan en Knulst 2000; van Eijck, de Haan en Knulst 2002).

Vóór de jaren zestig werd middelbare scholieren en zeker studenten in het wetenschappelijk onderwijs, respect voor de als hoger beschouwde cultuur bijgebracht. Eruditie en kennis van de klassieke en eigentijdse schone kunsten werden gepresenteerd als nastrevenswaardige zaken, waar 
men zich blijvend voor diende in te spannen. Het gedemocratiseerde middelbaar en hoger onderwijs heeft dit Bildungsideaal echter niet kunnen en willen overdragen. Het streven naar een alomvattende culturele vorming van individu en volk sneuvelde paradoxaal genoeg in het massaonderwijs.

Met de invoering van de Mammoetwet veranderde niet alleen de onderwijsstructuur, maar ook de aard en inhoud van het curriculum (Blom 1995; Schuyt en Taverne 2000). Het vroegere klassenverband maakte plaats voor het vakkenpakket, inclusief het beruchte 'pretpakket'. Leerlingen kregen de mogelijkheid om bepaalde vakken al vroeg in de opleiding te laten vallen. Niet iedereen deed bijgevolg nog eindexamen in vakken die relatief sterk bijdragen tot culturele kennis zoals geschiedenis en vreemde talen. Voor atheneumleerlingen vormden klassieke talen en cultuur geen verplicht onderdeel en aspirant-studenten konden bovendien via de omweg havo-hbo aan de universiteit terecht. Aangezien voor veel universitaire studies de eis van een gymnasiumopleiding verviel, nam het aantal klassiek geschoolde studenten aan Nederlandse universiteiten sterk af.

Traditionele onderwijsinhouden en lesmethoden stonden op gespannen voet met de toegenomen sociale heterogeniteit van de leerlingenpopulatie (Knippenberg en van der Ham 1993). Een groeiend aantal leerlingen was van huis uit niet vertrouwd met de culturele gedragscodes op school en aan de universiteit. Ook het gewijzigde karakter van de samenleving vroeg in de ogen van betrokkenen om een andere aanpak (de Winter 1995). De geëmancipeerde, geïndividualiseerde samenleving veronderstelde zelfstandige en weerbare burgers die zelf keuzes konden maken; het onderwijs diende jongeren daarop voor te bereiden. Last but not least eisten leerlingen en studenten zelf meer ruimte om binnen het onderwijs hun eigen interesses en voorkeuren te volgen.

Onder invloed hiervan verschoof het accent van een sterk leerstof- of cultuurgericht curriculum naar een meer 
leerling-gericht curriculum (Bronneman-Helmers 1999). Praktische kennis en vaardigheden kregen meer nadruk, ten koste van algemene kennis en brede culturele vorming. Zo nam binnen het vak Nederlands de aandacht voor taalbeheersing toe, terwijl literatuur steeds verder naar de periferie verdween (van de Ven 1996). De opmars van de informatiemaatschappij in de jaren tachtig en negentig leidde tot een verdere devaluatie van kennis an sich. De nadruk kwam steeds meer te liggen op het zelfstandig [leren] selecteren en verwerken van relevante kennis uit het groeiende en snel wisselende informatieaanbod.

De zojuist geschetste trends deden zich ook voor binnen het literatuuronderwijs en de kunstvakken. In het literatuuronderwijs kwam er naast de traditionele literatuur steeds meer ruimte voor zogeheten leerlinggerichte literatuur. De boekenlijst transformeerde tot het leesdossier, waarin een centrale rol is weggelegd voor de receptie van boeken door de leerling (Verboord 2003). Ook in het verplichte vak Cultuur en Kunstzinnige Vorming 1, dat eind jaren negentig werd ingevoerd, staan de eigen ervaring en beleving van de leerlingen centraal (Ganzeboom et al. 2003). Jongeren die na omstreeks 1955 opgroeiden, zijn dus op cultureel gebied anders 'geprogrammeerd' dan eerdere generaties (de Haan en Knulst 2000). Door veranderingen in het opvoedings- en onderwijsregime en de opkomst van een jeugdcultuur werden zij niet grootgebracht met het idee dat er een 'hoge' cultuur bestaat, die meer de moeite waard is dan de populaire cultuur. Zij kregen steeds meer gelegenheid om zich terug te trekken in een eigen smaakuniversum, waarin popmuziek, mode en sport prevaleren boven de traditionele hoge cultuur.

Die andere culturele programmering heeft niet alleen grote gevolgen gehad voor de smaakvoorkeuren en het gedrag van cultuurconsumenten. Ze heeft ook sterk doorgewerkt in de culturele opvattingen en beroepspraktijk van de talrijke hoger opgeleiden die in de jaren tachtig en negentig professioneel actief zijn geworden in kunst en media (Janssen 2003), onderwijs en openbaar bestuur en in die 
hoedanigheid het nodige hebben bijgedragen tot de verdere afbrokkeling van hiërarchische scheidslijnen tussen cultuurvormen.

\section{Tot slot}

Sinds de jaren vijftig zijn traditionele culturele hiërarchieën en scheidslijnen geërodeerd en vervangen door meer gedifferentieerde en minder hiërarchische patronen van cultuurproductie en cultuurconsumptie. Het culturele veld is een groeiend aantal geïnstitutionaliseerde genres gaan omvatten, die minder hiërarchisch geordend zijn dan voorheen. Actoren binnen het culturele veld zijn steeds meer verdeeld geraakt over de waarde van uiteenlopende cultuurvormen. Ook binnen afzonderlijke kunstsectoren is de consensus afgenomen over te hanteren beoordelingscriteria en daarmee verbonden classificaties van culturele producten.

Dit verlies aan hiërarchie en universaliteit manifesteert zich tevens in de consumptie van cultuur. Cultuurdeelnemers zijn steeds ongevoeliger geworden voor het traditionele onderscheid tussen hoge en lage cultuur en laten zich minder gelegen liggen aan critici en andere culturele autoriteiten. Culturele classificaties worden minder breed gedeeld en ook de mate waarin ze symbolische afgrenzingen tussen sociale groepen opleveren lijkt afgenomen.

Een en ander is het resultaat van diverse, onderling verweven bredere maatschappelijke en culturele processen en daarmee verbonden ontwikkelingen binnen het culturele veld zelf. Processen van individualisering en onthiërarchisering impliceerden dat culturele experts - net als andere autoriteiten - hun gezag zagen afbrokkelen en dat mensen ook op cultureel gebied steeds meer vrijheid kregen om te doen - of te laten - wat ze wilden. De postmammoet generaties hadden die keuzevrijheid al van jongs af aan door het liberalere, pedagogische regime waaronder zij opgroeiden. Zij kregen niet ingeprent dat de traditionele hogere cultuur waardevoller is dan andere cultuuruitingen. 
Zowel op school als in de vrije tijd konden zij tot op grote hoogte hun eigen voorkeuren volgen. Bovendien viel er ook steeds meer te kiezen.

Stijgende welvaart, de ontwikkeling van een omvattende, transnationale cultuurindustrie en de snel gegroeide verbreidingsmiddelen leidden tot een indrukwekkende expansie van de mogelijkheden voor cultuurconsumptie en vrijetijdsbesteding. Processen van ontstatelijking en de verscherpte concurrentie om de aandacht van cultuurconsumenten, dwongen traditionele kunstproducenten en -bemiddelaars om meer marktconform te opereren. Commerciële praktijken en classificatieprincipes werden bijgevolg steeds prominenter binnen de diverse kunstsectoren. In combinatie met de tanende, interne consensus onder kunstkenners leidde die 'vercommercialisering' tot een verdere uitholling van het idee dat Cultuur met een grote $C$ van een hogere orde zou zijn.

Dit alles impliceert niet dat de klassieke kunsten tegenwoordig geen speciale status meer genieten. Zo illustreren de opiniepagina's van de kwaliteitskranten en bijvoorbeeld ook de recente oraties van Maarten Doorman (2004) en Elsbeth Etty (2005) dat onder Nederlandse intellectuelen het draagvlak voor traditioneel als hoger beschouwde cultuurvormen nog altijd groot is. Maar het soortelijk gewicht van Kunst of Literatuur is vandaag de dag wel minder groot dan in de jaren vijftig of zestig. Men kan dat ontkennen, betreuren of via de (her)invoering van leeslijsten en canons proberen te bestrijden, maar die tijd komt nooit meer terug. Daarvoor zijn de geschetste veranderingsprocessen te fundamenteel en te vergevorderd. Een meeromvattende intellectuele en culturele vorming van nieuwe generaties vergt een veel radicalere herziening van het Nederlandse onderwijs (Blom 1995; Blom 2000) dan de meeste pleitbezorgers van een onderwijscanon voor ogen staat. De talrijke, ongewenste effecten van eerdere onderwijshervormingen doen echter vermoeden dat het middel wel eens erger zou kunnen zijn dan de kwaal. 
Dames en Heren,

Mijn leerstoel betreft de sociale aspecten van kunst, cultuur en media. Ik ben bijzonder blij met die opdracht, omdat hij zo'n beetje alles dekt waar ik me als docent en onderzoeker nu en in de toekomst op wil richten.

Ik heb geprobeerd $u$ een idee te geven van een aantal sociaal-culturele kwesties die me als wetenschapper interesseren en waar ik me binnen het VICI-project de komende jaren mee bezig zal houden.

Het is een voorrecht en steun dat ik dit grootschalige onderzoeksproject vanuit deze leerstoel kan uitvoeren. De Vereniging Trustfonds Erasmus Rotterdam en het College van Bestuur van deze universiteit ben ik erkentelijk voor het in mij gestelde vertrouwen. Dat geldt ook het bestuur en de collega's van de Faculteit der Historische en Kunstwetenschappen.

De Faculteit en vooral de vakgroep Kunst en Cultuurwetenschappen zijn voor mij steeds een vruchtbare en plezierige werkomgeving geweest, niet in de laatste plaats dankzij de geëngageerde en getalenteerde cultuur- en mediastudenten die ik in de loop van de tijd heb leren kennen.

Ik kijk met zeer veel genoegen terug op de pioniersjaren van de opleiding Kunst- en Cultuurwetenschappen, inmiddels getransformeerd tot de bachelor Algemene Cultuurwetenschappen en de master Kunst- en Cultuurwetenschappen.Van die periode heb ik veel geleerd, met name ook hoe inspirerend het is om in een hecht groepsverband te werken aan een onderneming waar je in gelooft. De andere KCW-ers van het eerste uur - Ton Bevers, Marlite Halbertsma, Berend- Jan Langenberg, Gabrielle Muris en Joop Visser ben ik nog steeds dankbaar voor die ervaring. 
Ik prijs me gelukkig dat ik een dergelijke grote teamgeest nu opnieuw ervaar in de samenwerking met de leden van de VICI-groep en de staf van de masteropleiding Media en Journalistiek.

Een aantal mensen wil ik speciaal bedanken:

Mijn Tilburgse leermeesters, Hugo Verdaasdonk en Kees van Rees, die met hun geestdrift en innovatieve aanpak mijn interesse voor de wetenschap hebben aangewakkerd en mij gestimuleerd hebben om mijn eigen weg daarin te vinden. Met name Kees van Rees is ook na mijn promotie een inspirator en mentor voor mij gebleven. Ik ben hem daar zeer erkentelijk voor.

Marianne de Jong, Nel van Dijk, Mijke Slot en Cecilia Gijtenbeek wil ik ook graag noemen: zij vertegenwoordigen voor mij respectievelijk de ideale vriendin, de ideale collega, de ideale master Media en de ideale oppasmoeder.

Mijn vader en moeder wil ik bedanken voor hun onvoorwaardelijke liefde en niet aflatende goede zorgen. Betere (groot)ouders kan een kind zich niet wensen.

Mijn zoon Ruben heeft mijn leven meer verrijkt dan ik voor mogelijk had gehouden.

Meer dan wie ook wil ik Borg danken, voor zijn grote wijsheid, liefde en steun.

Ik heb gezegd. 


\section{Noot}

* Dit is een door NWO en de Erasmus Universiteit Rotterdam gefinancierd grootschalig onderzoeksproject getiteld: Cultural classification systems in transition. The social valuation of cultural goods in France, Germany, the Netherlands and the United States 1955-2005. Zie http://www.fhk.eur.nl/onderzoek/viciproject/

\section{Literatuur}

van Alphen, E. en M. Meijer (red.) 1991. De canon onder vuur. Nederlandse literatuur tegendraads gelezen. Amsterdam: Van Gennep.

Baumann, S. (2001) Intellectualization and art world development: Film in the United States. American Sociological Review, 404-426.

- (2002) Marketing, cultural hierarchy, and the relevance of critics: film in the United States, 1935-1980. Poetics 30, 243-262.

Beck, U. (1986) Risikogesellschaft: auf dem Weg in eine andere Moderne. Frankfurt am Main: Suhrkamp.

Beck, U. en E. Beck-Gernsheim (2002) Individualization. Institutionalized individualism and its social and political consequences. London: Sage.

Beckers, T. en $\mathrm{H}$. van der Poel (1992) Vrije tijd tussen vorming en vermaak: een inleiding tot de studie van de vrije tijd. Leiden: Stenfert Kroese.

Bennet, T., M. Emmison en J. From (1999) Accounting for tastes: Every day cultures in the lifes of Australians. Cambridge, MA: Cambridge University Press.

Bevers, T. (2005) Cultural education and the canon. A comparative reserarch on the content of exams for music and art at secondary schools in Germany, France, England en the Netherlands 19902004. Poetics 33.

Bielby, W.T. en D.D. Bielby (1994) "All hits are flukes": Institutionalized decision making and the rethoric of network prime-time program development. American Journal of Sociology 99, 1287-1313.

Blom, S. (1995) Intellectuele vorming in Nederland en Frankrijk. Een vergelijkend onderzoek naar deelname aan intellectuele vorming in het Franse en Nederlandse voortgezet onderwijs. Groningen: Wolters-Noordhoff.

- (2001) Onderwijs en wetenschappelijke vorming. In: D. Fokkema en F. Grijzenhout (red.) Rekenschap, 1650-2000. Den Haag: SDU, 201-231. 
Boomgaard, J. en B. Rutten (2004) De magnetische tijd. Videokunst in Nederland, 1970-1985. Rotterdam: NAI Uitgevers.

Boorsma, P.B., A. van Hemel en R. van der Wielen (red.) 1997. Privatization and culture. Experiences in the arts, heritage and cultural industries in Europe. Dordrecht: Kluwer Academic Publishers.

Bos, J.E. (2001) Openbare schatkamers in verandering. Musea in Nederland in een tijd van verzelfstandiging en privatisering: Proefschrift Universiteit van Amsterdam.

Bourdieu, P. (1979) La distinction: critique sociale du jugement. Paris: Editions de Minuit.

- (1980) The production of belief: contribution to an economic of symbolic goods. Media, Culture \& Society 2, 261-293.

van den Broek, A. en K. Breedveld (red.) 2001. Trends in de tijd. Den Haag: SCP.

van den Broek, A., F. Huysmans en J. de Haan (2005) Cultuurminnaars en cultuurmijders. Trends in de belangstelling voor kunsten en cultureel erfgoed. Den Haag: SCP.

Bronneman-Helmers, H.M. (1999) Scholen onder druk. Op zoek naar de taak van de school in een veranderende samenleving. Den Haag: SCP.

Bryson, B. (1996) "Anything but heavy metal": symbolic exclusion and musical dislikes. American Sociological Review 61, 884-899.

- (1997) What about the univores? Musical dislikes and group-based identity construction among American with low levels of education. Poetics 25, 141-156.

- (2005) Making multiculturalism. Boundaries and meaning in U.S. English Departments. Palo Alto, CA: Stanford University Press.

Coulangeon, P. (2003) La stratification sociale des gouts musicaux. Le modele de la legitimite culturelle en question. Revue francaise de sociologie 44 ,

Crok, S. et al. (2002) Vrijetijdsbesteding jongeren in Amsterdam. Amsterdam: $\mathrm{O}+\mathrm{S}$, Amsterdams Bureau voor Onderzoek en Statistiek.

van Dijk, N. en S. Janssen (2001) De reuzen voorbij. De metamorfose van de literaire kritiek na 1965. In: J. Bardoel et al. (red.) Journalistieke cultuur in Nederland. Amsterdam: Amsterdam University Press, 208-235.

DiMaggio, P. (1987) Classification in Art. American Sociological Review, 440-455.

- (1991) Social structure, institutions and cultural goods. In: P. Bourdieu (red.) Social theory for a changing world. Boulder: Westview Press, 133-155. 
DiMaggio, P. en T. Mukhtar (2004) Arts participation as cultural capital in the United States, 1982-2002: Signs of decline? Poetics 32, 169-194.

Doorman, M. (2004) Kiekertak en Kloterbooke. Gedachten over de canon. Amsterdam: Vossiuspers AUP.

Dorleijn, G.J. en C.J. van Rees (red.) 1999. Literatuuropvattingen in het perspectief van het literaire veld. Den Haag: NWO.

Dowd, T.J. (2002) Organizing the musical canon: the repertoires of the major U.S. symphony orchestras, 1842-1969. Poetics, 35-61.

Dronkers, J. en W.C. Ultee (red.) 1995. Verschuivende ongelijkheid in Nederland. Sociale gelaagdheid en mobiliteit. Assen: Van Gorcum.

Duell, J. (2000) Assessing the literary: intellectual boundaries in French and American literary studies. In: M. Lamont en L. Thévenot (red.) Rethinking comparative cultural sociology. Repertoires of evaluation in France and the United States. Cambridge:

Cambridge University Press, 94-124.

van Dulken, H. (2002) Sanering van de subsidiering:

overheidsbemoeienis met monumentenzorg, film en toneel vanaf de jaren zestig. Amsterdam: Boekmanstudies.

van Eijck, K. (1999) Socialization, education and lifestyle. How social mobility increases the cultural heterogenity of status groups. Poetics, 309-328.

- (2001) Social differentiation in musical taste patterns. Social Forces 79, 1163-1185.

van Eijck, K., J. de Haan en W. Knulst (2002) Snobisme hoeft niet meer. De interesse voor hoge cultuur in een smaakdemocratie. Mens en maatschappij 77, 153-177.

Elchardus, M., A. Faelens en T. Kuppens (2002) Autochtone en allochtone paden in de Vlaamse massacultuur. In: M. Elchardus en I. Glorieux (red.) De symbolische samenleving. Een exploratie van de nieuwe sociale en culturele ruimtes. Tielt: Lannoo, 337361.

Elffers, A., C. van der Hoeven en L. Ranshuysen (2004) Gezocht: Jonge theaterbezoekers. Onderzoek naar succesvolle methodieken voor jongerenmarketing in de podiumkunsten. Rotterdam: Onderzoeksbureau Letty Ranshuysen.

Etty, E. (2005) Galopperend op jacht naar een idee: literaire kritiek als journalistiek genre. Amsterdam: VU Boekhandel/Uitgeverij.

Franke, H. (2000) Een verplattingsoffensief. NRC Handelsblad, 14 april.,

Ganzeboom, H. (1996) Onderwijsexpansie en onderwijskansen. In: H.B.G. Ganzeboom en W.C. Ultee (red.) De sociale segmentatie van Nederland in 2015. Den Haag: Sdu Uitgevers, 13-48. 
Ganzeboom, H. et al. (2003) Momentopnames CKV1. Eindrapportage CKV1-Volgproject. Utrecht: Cultuurnetwerk Nederland.

Giddens, A. (1991) Modernity and self-identity. Self and society in the late modern age. Cambridge: Polity Press.

de Goede, P. (1999) Omroepbeleid met en tegen de tijd. Interacties en instituties in het Nederlandse omroepbestel 1919-1999.

Amsterdam: Otto Cramwinckel.

Goedegebuure, J. en O. Heynders (1996) Literatuurwetenschap in Nederland: een vakgeschiedenis. Amsterdam: Amsterdam University Press.

Gorak, J. (1991) The making of the modern canon. Genesis and crisis of a literary idea. London: Athlone.

de Haan, J. en W. Knulst (2000) Het bereik van de kunsten. Een onderzoek naar de veranderingen in de belangstelling voor beeldende kunst en podiumkunst sinds de jaren vijftig. Den Haag: SCP.

Janssen, S. (1999) Art journalism and cultural change: The coverage of the arts in Dutch newspapers 1965-1990. Poetics 26, 329-348.

- (2003) Kunstjournalisten in de kijker. Een onderzoek naar de achtergrondkenmerken, beroepspraktijk en professionele opvattingen van kunstmedewerkers van Nederlandse dag- en weekbladen. Boekman 15, 15-26.

Janssen, T. (1998) Literatuuronderwijs bij benadering. Een empirisch onderzoek naar de vormgeving en opbrengsten van het literatuuronderwijs Nederlands in de bovenbouw van het havo en vwo. Amsterdam: Thesis Publishers.

van Kemenade, J.A. et al. (red.) 1986. Onderwijs: bestel en beleid 1. Onderwijs in hoofdlijnen. Groningen: Wolters-Noordhoff.

Knippenberg, H. en W. van der Ham (1993) Een bron van aanhoudende zorg: 75 jaar ministerie van Onderwijs (Kunsten) en Wetenschappen. Assen: Van Gorcum.

Knulst, W. (1989) Van vaudeville tot video. Een empirisch-theoretische studie naar verschuivingen in het uitgaan en gebruik van media sinds de jaren vijftig. Rijswijk: SCP.

Knulst, W. en G. Kraaykamp (1996) Leesgewoonten. Een halve eeuw onderzoek naar het lezen en zijn belagers. Den Haag: SCP.

Lamont, M. (1992) Money, morals and manners. The culture of the French and American upper-middle class. Chicago: University of Chicago Press.

Lamont, M. en L. Thévenot (2000) Rethinking comparative cultural sociology. Repertoires of evaluation in France and the United States. Cambridge, MA: Cambridge University Press.

Lauter, P. (1991) Canons and Contexts. New York: Oxford University Press. 
Levine, L.W. (1988) Highbrow, lowbrow: the emergence of cultural hierarchy in America. Cambridge, MA: Harvard University Press.

Lopez-Sintas, J. en E. Garcia-Alvarez (2002) Omivores show up again. The segmentation of consumers in Spanish social space. European Sociological Review 18, 353-368.

- (2004) Omnivore versus univore consumption and its symbolic properties: evidence from Spaniards performing arts attendance. Poetics 32, 463-483.

Mathijsen, M., H. Pleij en T. Vaessens (2005) Dit zijn de boeken die iedereen eigenlijk gelezen moet hebben. NRC Handelsblad, 5 en 6 maart.

McQuail, D. (1997) Audience analysis. Thousand Oaks, CA: Sage.

Meijer, M. (1988) De lust tot lezen. Nederlandse dichteressen en het literaire systeem. Amsterdam: Sara/Van Gennep.

Moerbeek, J. (1998) Canons in context: canonvorming in het literatuuronderwijs in Nederland en Vlaanderen. Utrecht: Dissertatie Universiteit Utrecht.

Mommaas, H. (2000) De vrijetijdsindustrie in stad en land. Een studie naar de markt van belevenissen. Den Haag: SDU Uitgevers.

Munters, Q.J. (1977) Stijgende en dalende cultuurgoederen. De "open" samenleving ter discussie. Alphen aan den Rijn: Samson.

Mutsaerts, L. (2004) Is everybody happy? Een opiniërend essay over de popmuzieksector in Nederland in het licht van de cultuurnotaperiode 2005-2008. Den Haag: Ministerie van OCW.

Negus, K. (1999) Music genres and corporate cultures. London: Routledge.

Nochlin, L. (1971) Why have there been no great women artists? Art News 69,

Nuchelmans, A. (2002) 'Dit gebonk dient tot het laatste toe te worden bestreden' Popmuziek en overheidsbeleid 1975-2001. Amsterdam: Boekmanstudies.

Obbema, F. (2003) Allochtoon verkoopt niet. De Franse literaire wereld kijkt liever naar kwaliteit dan naar herkomst. De Volkskrant, 21 maart.

OCW (2002) Cultuurbeleid in Nederland 2002. Den Haag: Ministerie van Onderwijs, Cultuur en Wetenschap.

Oosterbaan Martinius, W. (1990) Schoonheid, welzijn, kwaliteit. Kunstbeleid en verantwoording na 1945. Den Haag: Gary Schwartz / SDU.

Peterson, R.A. (1997) The rise and fall of highbrow snobbery as status marker. Poetics 25, 75-92.

Peterson, R.A. en R. Kern (1996) Changing highbrow taste: From snob to omnivore. American Sociological Review 61, 900-907. 
Peterson, R.A. en A. Simkus (1992) How Musical Tastes Mark

Occupational Status Groups. In: M. Lamont en M. Fournier (red.)

Cultivating differences: Symbolic boundaries and the making of inequality. Chicago: University of Chicago Press,

Pinto, D. (1988) Toward a mellowing of the French identiy. In: J. Howorth en G. Ross (red.) Contemporary France. A review of interdisciplinary studies. Londen: Frances Pinter,

Pol, M.v.d. en E. Duijser (2004) Marktbeschrijving podiumkunsten 2004. Onderzoek onder de Nederlandse bevolking. TNS-Nipo in opdracht van Bureau Promototie Podiumkunsten.

Pots, R. (2000) Cultuur, koningen en democraten. Overheid \& cultuur in Nederland. Nijmegen: SUN.

van Rees, C.J., S. Janssen en M. Verboord (2005) Classificatie in het culturele en literaire veld 1975-2000. Diversificatie en nivellering van grenzen tussen genres. In: G.J. Dorleijn en C.J. van Rees (red.) Het literaire veld 1800-2000. Nijmegen: Van Tilt.

van Rees, C.J., J. Vermunt en M. Verboord (1999) Cultural classifications under discussion. Latent class analysis of highbrow and lowbrow reading. Poetics 26, 349-365.

Righart, H. (1995) De eindeloze jaren zestig. Geschiedenis van een generatieconflict. Amsterdam: De Arbeiderspers.

Schnabel, P. (2004) Het zestiende Sociaal en Cultureel Rapport kijkt zestien jaar vooruit. In: SCP (red.) Sociaal en Cultureel Rapport 2004. In het zicht van de toekomst. Den Haag: SDU, 47-90.

Schulze, G. (1992) Die Erlebnis-Gesellschaft: Kultursoziologie der Gegenwart. Frankfur/Main: Campus Verlag.

Schuyt, K. en E. Taverne (2000) 1950. Welvaart in zwart-wit. Den Haag: SDU Uitgevers.

SCP (2000) Sociaal en Cultureel Rapport 2000. Nederland in Europa. Den Haag: SCP.

de Swaan, A. (1979) Uitgaansbeperking en uitgaansangst. Over de verschuiving van de bevelshuishouding naar onderhandelingshuishouding. Amsterdam: De Gids/Meulenhoff.

- (1986) Kwaliteit is klasse. Amsterdam: Bert Bakker.

Szanto, A.e.a. (2000) Reporting the arts: news coverage of arts and culture in America. New York: NAJP/Columbia University.

Tillekens, G. (red.) 1990. Nuchterheid en nozems. De opkomst van de jeugdcultuur in de jaren vijftig. Muiderberg/Amsterdam: Coutinho/Siswo.

Vander Stichele, A. en R. Laermans (2004) Cultuurparticipatie in Vlaanderen: een toetsing van de these van de culturele omnivoor. Tijdschrift voor Sociologie 25, 195-219. 
van de Ven, P.H. (1996) Moedertaalonderwijs. Interpretaties in retoriek en praktijk, heden en verleden, binnen- en buitenland. Groningen: Wolters-Noordhof.

Verboord, M. (2003) Moet de meester dalen of de leerling klimmen? De invloed van literatuuronderwijs en ouders op het lezen van boeken tussen 1975 en 2000. Utrecht: ICTS.

Vogelaar, J.F. (red.) 1972. Kunst als kritiek: voorbeelden van een materialistische kunstopvatting. Amsterdam: Bezige Bij.

Weber, D. (2000) Culture or commerce? Symbolic boundaries in French and American book publishing. In: M. Lamont en L. Thévenot (red.) Rethinking comparative cultural sociology. Repertoires of evaluation in France and the United States. Cambridge, MA: Cambridge University Press, 127-147.

Wijfjes, H. (red.) 1994. Omroep in Nederland. Vijfenzeventig jaar medium en maatschappij, 1919-1994. Zwolle: Waanders.

Wilterdink, N. (2000) In deze verwarrende tijd. Een terugblik en vooruitblik op de postmoderniteit. Amsterdam: Vossiuspers AUP. de Winter, M. (1995) Kinderen als medeburgers. Kinder-en jeugdparticipatie als maatschappelijk opvoedingsperspectief. Utrecht: De Tijdstroom. 